\title{
An improved technique for estimating short-term survival of released line-caught fish, and an application comparing barotrauma-relief methods in red emperor (Lutjanus sebae Cuvier 1816)
}

\author{
I. Brown ${ }^{\text {a,* }}$, W. Sumpton a , M. McLennan ${ }^{\text {a }}$, D. Mayer ${ }^{\text {b }}$, M. Campbell ${ }^{\text {a }}$, J. Kirkwood ${ }^{\text {a }}$, A. Butcher ${ }^{\text {a }}$, I. Halliday ${ }^{\text {a }}$, \\ A. Mapleston ${ }^{\text {, }}$ D. Welch ${ }^{\text {c,e }}$, G.A. Begg ${ }^{\text {c,1 }}$, B. Sawynok ${ }^{\mathrm{d}}$ \\ a Southern Fisheries Centre, Department of Employment, Economic Development and Innovation, Agri-Science Queensland, PO Box 76, Deception Bay 4508, Queensland, Australia \\ ${ }^{\mathrm{b}}$ Animal Science Institute, Department of Employment, Economic Development and Innovation, Agri-Science Queensland, 665 Fairfield Rd. Yeerongpilly 4105 , Queensland, Australia \\ ' Fish and Fisheries Research Centre, James Cook University, Townsville 4811, Queensland, Australia \\ d Infofish Services Inc., 142 Venables St North Rockhampton 4701, Queensland, Australia \\ e Northern Fisheries Centre, Department of Employment, Economic Development and Innovation, Agri-Science Queensland, PO Box 5396 Portsmith 4870, Queensland, Australia
}

\section{A R T I C L E I N F O}

Article history:

Received 7 April 2009

Received in revised form 11 January 2010

Accepted 12 January 2010

\section{Keywords:}

Barotrauma

Lutjanus sebae

Post-release survival

Red emperor

Release weight

Survival

Venting

\begin{abstract}
A B S T R A C T
Promotion of better procedures for releasing undersize fish, advocacy of catch-and-release angling, and changing minimum legal sizes are increasingly being used as tools for sustainable management of fish stocks. However without knowing the proportion of released fish that survive, the conservation value of any of these measures is uncertain. We developed a floating vertical enclosure to estimate short-term survival of released line-caught tropical and subtropical reef-associated species, and used it to compare the effectiveness of two barotrauma-relief procedures (venting and shotline releasing) on red emperor (Lutjanus sebae). Barotrauma signs varied with capture depth, but not with the size of the fish. Fish from the greatest depths (40-52 $\mathrm{m}$ ) exhibited extreme signs less frequently than did those from intermediate depths ( $30-40 \mathrm{~m}$ ), possibly as a result of swim bladder gas being vented externally through a rupture in the body wall. All but two fish survived the experiment, and as neither release technique significantly improved short-term survival of the red emperor over non-treatment we see little benefit in promoting either venting or shotline releasing for this comparatively resilient species. Floating vertical enclosures can improve short-term post-release mortality estimates as they overcome many problems encountered when constraining fish in submerged cages.
\end{abstract}

Crown Copyright @ 2010 Published by Elsevier B.V. All rights reserved.

\section{Introduction}

Fish caught by hook and line may sustain injury from poor handling practices (Diodati and Richards, 1996; Meka, 2004; Bartholomew and Bohnsack, 2005; Grixti et al., 2007), hook damage (Muoneke and Childress, 1994; Cooke et al., 2003) or the effects of pressure reduction as they are brought to the surface (Feathers and Knable, 1983; Rummer and Bennett, 2005; Rogers et al., 2008). These injuries may lead to reduced physiological fitness or reproductive potential, or in extreme cases to acute or delayed mortality.

The signs and effects of capture depth on pressure-related injury or barotrauma in fish have been well documented (e.g. Bruesewitz et al., 1993; St John and Syers, 2005; Gravel and Cooke, 2008; Hannah et al., 2008). One consistent and obvious external sign of barotrauma is an enlargement of the body cavity due to distension of the swim

\footnotetext{
* Corresponding author. Tel.: +61 73817 9580; fax: +61 738179555.

E-mail address: ian.brown@dpi.qld.gov.au (I. Brown).

${ }^{1}$ Present address: Bureau of Rural Sciences, Box 7051, Canberra Business Centre, Canberra 2610, ACT, Australia.
}

bladder, causing the fish to become positively buoyant and experience difficulty in submerging when released, thus increasing its vulnerability to near-surface predators (Collins, 1991; Bruesewitz et al., 1993). Signs of more serious barotrauma include gut eversion, with part of the alimentary canal protruding from the mouth, vent or gill cavity; exophthalmia (bulging eyes); and external haemorrhaging around the vent. These visible signs constitute part of an extensive suite of external and internal symptoms described by Rummer and Bennett (2005).

Two principal methods of relieving the effects of barotrauma venting and shotline releasing - are presently used by anglers. Recommended for some years by the angling industry in the U.S. (Florida Sea Grant, 2005) and more recently in Australia by the national Recfishing Research programme ${ }^{2}$, venting involves deflating the distended swim bladder by puncturing the body wall with a hollow needle. The less-publicised shotline or release-weight releasing method involves compressing the swim bladder to its original

\footnotetext{
2 http://www.recfishresearch.org/.
} 
volume by forcing the fish back down to its capture depth. This is achieved by attaching the fish to a barbless hook embedded in a lead weight, lowering it to its capture depth where it is assumed to become neutrally buoyant, then releasing it by jerking the line (Bartholomew and Bohnsack, 2005).

Studies examining the effectiveness of venting as a barotraumamitigation procedure have yielded inconsistent results. Venting improved the survival rate of released black sea bass and vermilion snapper (Collins et al., 1999), groupers (Wilson and Burns, 1996) and yellow perch (Keniry et al., 1996), but had no positive effect on the survival of rockfish (Gotshall, 1964), burbot (Bruesewitz et al., 1993), or red snapper (Render and Wilson, 1994). A meta-analysis of 17 published and unpublished studies concluded that venting may actually be detrimental as a conservation measure (Wilde, 2009). The releaseweight technique has been promoted by some agencies as a preferred alternative to venting, but its effectiveness for mitigating the effects of barotrauma has yet to be formally evaluated (Bartholomew and Bohnsack, 2005).

Enclosed submerged cages have often been used in studies of shortterm post-release survival of barotrauma-affected fish (Collins, 1991; Wilson and Burns, 1996; Collins et al., 1999; St John and Syers, 2005; Jarvis and Lowe, 2008; Stewart, 2008). However in experiments testing the effects of barotrauma remediation procedures, submerged cages are inappropriate, as they do not provide for untreated controls - i.e. fish that have received no other remediation treatment. Forcing non-vented fish to the bottom in a cage does not constitute 'non-treatment', but is itself a treatment which partially approximates the shotline release, an issue recognised by St John and Syers (2005). The cage option is also a poor simulation of reality in that it fails to reflect the sequence of events typically experienced by fish released after being caught and brought to the surface. Untreated release occurs frequently in reality, and may result in bloated fish either recovering to the extent that they are able to swim down to equilibrium depth, or alternatively being preyed upon by one of a number of potential predators (Keniry et al., 1996). Submerged cages do not allow these possibilities to be examined, even qualitatively (Pollock and Pine, 2007). This was recognised by Hannah et al. (2008), who used bottomless floating enclosures to examine the effect of size and capture depth on the ability of rockfish to resubmerge after capture. Once a fish is caught and vented (or not, according to the experimental design) it should be released as soon as practicable to avoid exposure to unduly long and variable surface intervals (i.e. the time between capture and release). When the time between successive captures exceeds $10-15 \mathrm{~min}$, it is not possible to place more than a few fish in a cage without seriously extending the surface interval.

As submerged cages cannot be used to test the relative effectiveness of the two release methods, we designed a vertical enclosure to contain the treated fish. The advantages of this system are that (a) it allows untreated controls to be included in the experimental design (i.e. the apparatus itself does not constitute a treatment, as it does in the case of the cages); (b) it provides an environment into which fish can be released with the aid of a shotline or release weight; (c) it provides some insights into the situation where a released fish may drift on the surface after release, during which time (in its natural environment) it could be at risk of predatory mortality; (d) it can reduce the surface interval by allowing marked fish to be introduced into the apparatus at any time; and (e) it improves the efficiency of the experiment by enabling more fish (up to 30 or 40 ) to be held in the apparatus at any given time.

Henry and Lyle (2003) estimated that about half of the Australian recreational catch of line-caught fish (by number) is discarded or released. The application of increasingly stringent minimum legal size (MLS) and bag limits as management mechanisms for maintaining effective spawning stock sizes and limiting catches is likely to increase the releasing rate in many of these fisheries. For example, the change in MLS for red emperor (Lutjanus sebae) from 45 to $55 \mathrm{~cm}$ in 2003 (Sumpton et al., 2008) resulted in an increase in the discarding rate of this species in both the commercial and recreational sectors.
Recreational releasing of red emperor increased from 69\% in 2002 to $83 \%$ in 2005 , and the retained catch dropped correspondingly from $393 \mathrm{t}$ to $232 \mathrm{t}$ over the same period (Coastal Habitat Resources Information System, Department of Employment, Economic Development and Innovation). Commercial landings of red emperor in Queensland also decreased from annual averages of $163 \mathrm{t}$ over the four year period 2000-2003 to $37 \mathrm{t}$ over the four years from 2004 to 2007 (Commercial Fisheries Catch and Effort Database, DEEDI). Such high levels of releasing have raised concerns about the extent of associated cryptic post-release mortality, a potentially important but unquantified component of fishing mortality.

In this study we first evaluated the vertical enclosures by comparing the survival rates of red emperor held in submerged cages and enclosures. We investigated whether fish could equilibrate at a shallower depth than that from which they were caught, as (from Boyle's Law) the effects of pressure differences on swim bladder volume are proportionately greater in shallower than deeper water. We then used the vertical enclosures to test the effectiveness of two barotrauma-relief procedures (venting and shotline releasing) on the short-term survival of this popular angling species.

\section{Materials and methods}

\subsection{Experimental site selection}

An area north of Double Island Point, Queensland, Australia $\left(25^{\circ} 55^{\prime} \mathrm{S}\right.$, $153^{\circ} 11^{\prime} \mathrm{E}$; Fig. 1) was chosen as the main site of this experiment because of its proximity to reefs supporting populations of red emperor. Additional data on a small number of red emperor were collected from a site off the north-east corner of Heron Island Reef $\left(23^{\circ} 25^{\prime}\right.$ S, $151^{\circ} 59^{\prime} \mathrm{E}$; Fig. 1) during subsequent survival experiments on other reef fish species.

\subsection{Apparatus design}

Cages were slightly larger than those used successfully by St John and Syers (2005), and of similar design to the collapsible pots used in the Queensland blue swimmer crab fishery (Campbell and Sumpton, 2008). They consisted of two $1 \mathrm{~m}$ diameter metal hoops separated by four $350 \mathrm{~mm}$ high tubular PVC risers and were covered with either $50 \mathrm{~mm} \times 36$ ply orange nylon mesh or $25 \mathrm{~mm} \times 9$ ply blue nylon mesh. Fish were placed into the cage via a drawstring-constrained opening in the upper surface. Cages were deployed in strings of four. The first cage was suspended (at 15 or $30 \mathrm{~m}$ depth) from a surface float which was moored by a $10 \mathrm{~kg}$ anchor on $60 \mathrm{~m}$ of rope, and trailed a dan-buoy with radar reflector, flag and night-light. The second cage, with its own surface float, was attached to the first cage's float line via a $15 \mathrm{~m}$ line with a stainless steel clip-ring which slid down the first float line to the top of the first cage. This arrangement allowed each successive cage to be deployed and retrieved with minimal disturbance to the previous one.

Vertical enclosures were cylinders $1.9 \mathrm{~m}$ in diameter and $15 \mathrm{~m}$ in depth. Eight horizontal steel hoops were separated by $2.5 \mathrm{~m}$ of $101 \mathrm{~mm} \times 36$ ply brown mesh, except for the top two hoops which were held $0.5 \mathrm{~m}$ apart by solid welded rods (Fig. 2). Four inflatable plastic floats were attached to the inside of the second metal ring to give the apparatus positive buoyancy at the surface. The eighth (bottom) ring was $15 \mathrm{~m}$ below the surface and weighted with three $13 \mathrm{~kg}$ lead blocks to keep the net vertical in a current. A $20 \mathrm{~m} \times 12 \mathrm{~mm}$ retrieval rope was connected to a $1.2 \mathrm{~m}$ 4-arm 'spider' chain, which was in turn attached to the seventh spacer ring $2.5 \mathrm{~m}$ from the bottom of the apparatus. The retrieval rope was held centrally inside the top ring by a $50 \mathrm{~mm}$ stainless steel locating ring. On retrieval by crane, the apparatus collapsed in concertina-fashion except for the bottom-most compartment holding the fish, which could then be released from the cod end of the enclosure. Each enclosure was moored by two in-line 


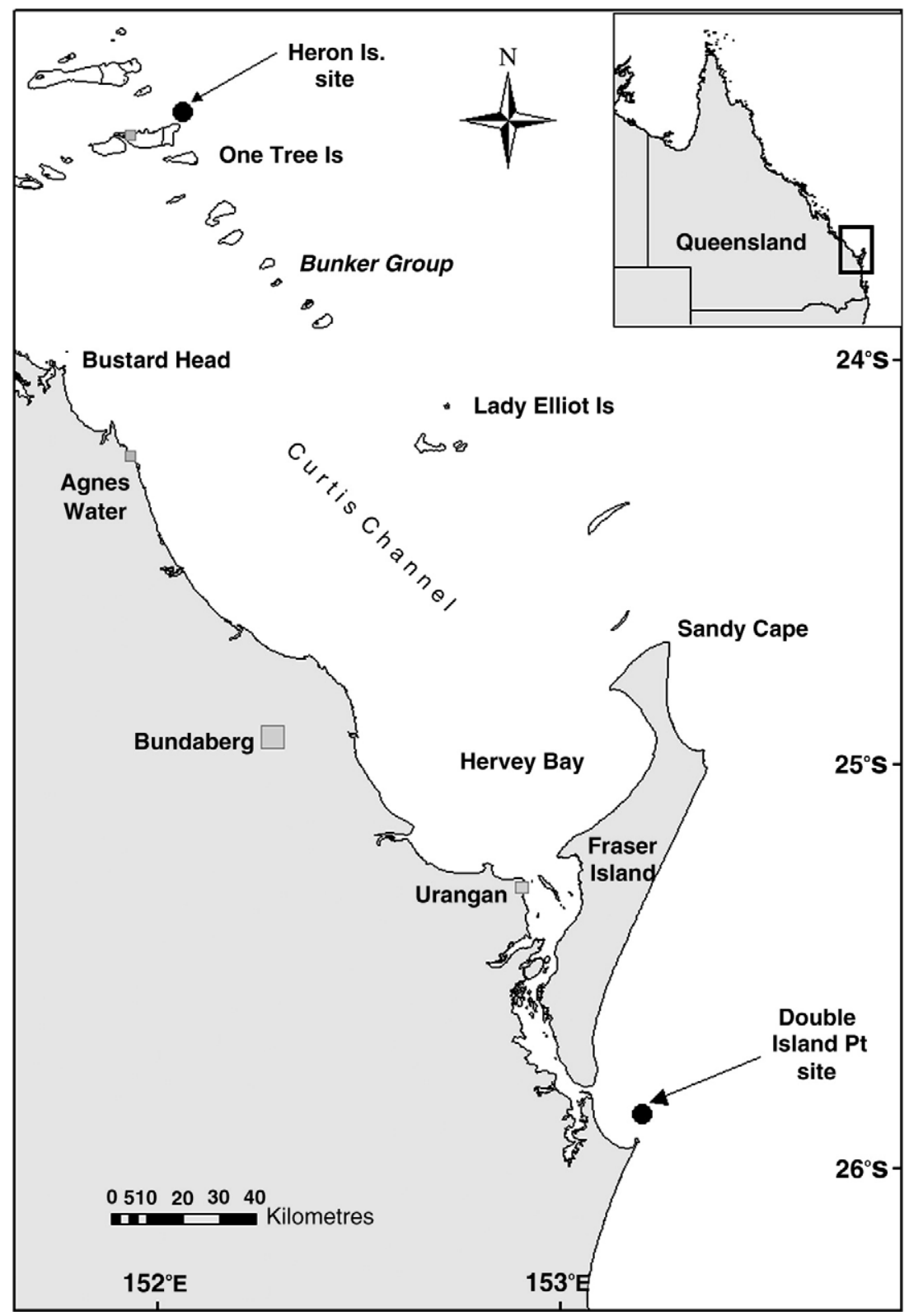

Fig. 1. Location of post-release survival experiment sites in south-central Queensland.

anchors ( $16 \mathrm{~kg}$ and $10 \mathrm{~kg}$ ) linked by $10 \mathrm{~m}$ of $8 \mathrm{~mm}$ chain and $60 \mathrm{~m}$ of $12 \mathrm{~mm}$ diameter anchor rope. A dan-buoy with radar reflector was attached directly to the retrieval rope on the second enclosure and floated approximately $5 \mathrm{~m}$ downwind. Net lights were attached to the upper ring of each enclosure and to the cage arrays.

\subsection{Comparison of cages and vertical enclosures}

A preliminary experiment carried out in August 2004 at Double Island Pt (Fig. 1) compared survival rates of fish captured from depths of 30-50 $\mathrm{m}$ and released either into an enclosure (control, shotlined or vented), or submerged in cages (no treatment). Each cage contained a maximum of three fish, and two cages were assigned to each of the two depths ( 15 and $30 \mathrm{~m}$ ).

\subsection{Experimental protocols}

Data for each fish recorded at the point of capture included time of day, species, fork length (FL), hook type and size, capture depth, hook penetration location (lip, mouth, throat, gut or other/foul), hook damage (mouth, gill, and eye), evidence of bleeding or scale loss (nil, slight or severe), and external signs and extent of barotrauma (nil, bloating, gut extrusion and/or exophthalmia). After insertion of a numbered HallPrint ${ }^{\mathrm{TM}}$ dart tag into the dorsal musculature, the fish was placed into a holding tub filled with seawater, then transported to the cage array or enclosure. While the interval between capture and release into the experimental apparatus was kept to a minimum, the distance between the fishing location and the moored enclosures, which ranged up to about $15 \mathrm{~km}$, meant that in some cases the time interval would far exceed that occurring in a typical recreational angling context. Details of the times of capture and release into the experimental apparatus were therefore recorded. Fish destined for the cages were not treated, while those destined for the vertical enclosures were either left as untreated controls, vented, or released into the enclosure using a shotline. The two treatments and control were done sequentially to provide approximately equal numbers of replicates. The condition of vented and control fish on release into the enclosure was assessed subjectively and given a score from 


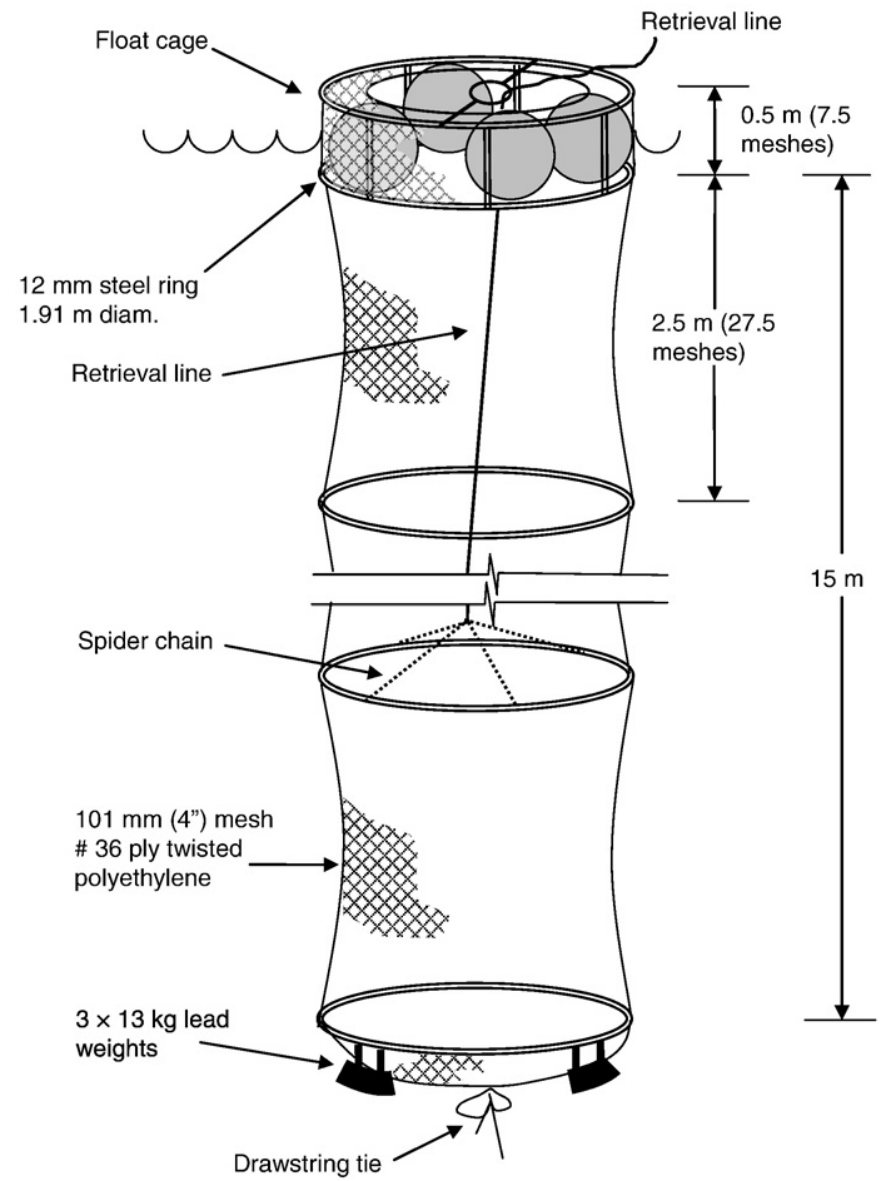

Fig. 2. Diagrammatic representation of the vertical enclosure (not to scale). Mooring tackle and safety lights are not shown.

1 (excellent condition, with the fish submerging and swimming down strongly) to 5 (moribund or probably dead). It was not possible to assess the condition of shotline-released fish in the same way, as these fish were forced to the bottom of the enclosure.

Fish were vented by puncturing the swim bladder with a $38.1 \times$ $1.6 \mathrm{~mm}$ (1.5 in. $\times 16$-gauge) monoject hypodermic needle attached to a disposable $3 \mathrm{ml}$ plastic syringe barrel with the plunger removed. The needle was inserted under a scale through the body wall in line with the top of the pectoral fin base and below the fourth dorsal spine. Once the epidermis had been punctured the syringe was lifted to a more vertical orientation with respect to the side of the fish, and inserted through the musculature into the swim bladder. A successful procedure was indicated by the audible hiss of gas escaping through the syringe, facilitated if necessary by gentle pressure on the body wall. During the experimental period the behaviour and condition of the fish in the vertical enclosures were observed by underwater video camera lowered from the surface, and periodic observations on the enclosures were also made by SCUBA-equipped divers. After each enclosure or line of cages had been deployed for 3 days the apparatus were retrieved, the condition of each fish noted together with its tag number, and the survivors released.

\subsection{Effect of release method on survival}

The results of the preliminary experiment demonstrated the superiority of vertical enclosures over small cages for testing shortterm survival in the red emperor. None of the 34 red emperor contained in the submerged cages survived the experimental period, regardless of the capture depth or the depth at which the cages were suspended, while all 35 fish released into the vertical enclosures were alive and in excellent condition when retrieved at the conclusion of the experiment. Although the maximum depth to which the fish could submerge in the enclosures was limited to $15 \mathrm{~m}$ (compared to $30 \mathrm{~m}$ for half of the submerged cages), this result justified the continued use of floating vertical enclosures for comparing the effectiveness of the two release methods.

Data relating to fish held in the enclosures during the preliminary experiment were supplemented with additional data from two operations near Heron Island (March and June 2005) and Double Island Point (July 2005) for the release-method comparison. Experimental protocols relating to the deployment of enclosures, barotrauma treatment and data collection in the subsequent operations were the same as those in the preliminary experiment.

\subsection{Data analysis}

Binary survival data from the release-method experiment were analysed by multi-factor generalised linear models or GLMs (McCullagh and Nelder, 1989) in GenStat (2007). The models were run under the binomial distribution with logit link function, and with block (a combination of trip and enclosure number), entry condition, and treatment as the predictor variates. The effects of capture depth and body size on the incidence of barotrauma were analysed by GLM, again with binomial distribution and logit link. The low frequency of records with barotrauma signs other than bloating or swelling of the body cavity required pooling of the data into a simple binary presence-absence field.

\section{Results}

\subsection{Depth equilibration}

Along with the treated fish, twelve untreated controls were distributed between the two vertical enclosures in the preliminary experiment. These fish all submerged and immediately swam down into the enclosures when released. Periodic observations over the next three days by divers and underwater video revealed that all fish were swimming about $1 \mathrm{~m}$ above the bottom-most ring, apparently with no adverse equilibration effects. The fish appeared unstressed, frequently approaching the camera and divers in an inquisitive manner.

\subsection{Comparison of barotrauma-relief release methods}

Over the period of the four field trials at Double Island Point and Heron Island, 142 red emperor were captured, tagged, treated according to the experimental protocols, and introduced into one of three identical vertical enclosures. Eighteen fish disappeared from the enclosures during the course of the experiment (Table 1), as a result of tilting of the enclosures or shark damage to the mesh at Heron Is., or damage by an unidentified vessel at Double Island Pt. From the tag numbers of the fish remaining in the enclosure we determined that the lost fish comprised seven control, seven shotline released and four vented individuals. The small difference between these numbers suggests that treatment was not likely to have been associated with their disappearance, and these fish were therefore excluded from further analyses of survival rates.

The only mortalities were two fish that had been released into separate enclosures by shotline, with the result that the overall survival rate of red emperor in this experiment was $98.4 \%$. The two were of similar sizes ( 32 and $30.5 \mathrm{~cm} \mathrm{FL),} \mathrm{and} \mathrm{had} \mathrm{been} \mathrm{caught} \mathrm{by}$ different anglers in depths near opposite extremes of the range of the reported capture depths ( 32 and $49 \mathrm{~m}$ ). The smaller individual had been hooked in the throat and subjected to an unusually long surface interval ( $3.2 \mathrm{~h}$ ), but there were otherwise no data that could identify either fish as being at greater risk of mortality than others used in the 
Table 1

Fate of fish held in the experimental enclosures during each of the four field trials.

\begin{tabular}{llrrrrr}
\hline \multirow{2}{*}{ Treatment } & Fate & \multicolumn{2}{c}{ Trial number } & Total \\
\cline { 2 - 5 } & & 1 & 2 & 3 & 4 & \\
\hline \multirow{2}{*}{ Control } & Survived & 12 & 1 & 1 & 27 & 41 \\
& Died & 0 & 0 & 0 & 0 & 0 \\
& Missing & 0 & 1 & 0 & 6 & 7 \\
\multirow{5}{*}{ Vented } & Total & 12 & 2 & 1 & 33 & 48 \\
& Survived & 11 & 1 & 0 & 30 & 42 \\
& Died & 0 & 0 & 0 & 0 & 0 \\
Shotline released & Missing & 0 & 0 & 0 & 4 & 4 \\
& Total & 11 & 1 & 0 & 34 & 46 \\
& Survived & 12 & 1 & 0 & 26 & 39 \\
& Died & 0 & 0 & 0 & 2 & 2 \\
Total & Missing & 0 & 1 & 0 & 6 & 7 \\
& Total & 12 & 2 & 0 & 34 & 48 \\
& Survived & 35 & 3 & 1 & 83 & 122 \\
& Died & 0 & 0 & 0 & 2 & 2 \\
& Missing & 0 & 2 & 0 & 16 & 18 \\
& Total & 35 & 5 & 1 & 101 & 142 \\
\hline
\end{tabular}

experiment. Because of the very high survival rate, it is not surprising that none of the variables of interest (enclosure-site, surface interval, entry condition or treatment) had a statistically significant effect on mortality.

\subsection{Effect of capture depth and body size on barotrauma}

Of the 166 fish examined immediately after capture, fewer than $20 \%$ showed any external signs of barotrauma, and almost all of these (19.9\%) were classed as swollen or bloated. Gut extrusion was reported in only six individuals (3.6\%). Initial data exploration determined appropriate class-widths for pooling fish length data ( $\leq 35$ and $>35 \mathrm{~cm} \mathrm{FL}$ ) and capture depth information $(<25,25-39,40-45$, and $>45 \mathrm{~m}$ ) for GLM analysis. Neither fish length nor its interaction term was significant at the $95 \%$ level, so length was dropped from the model, simplifying it to the main effect of depth, which was highly significant at $P<0.001$. The adjusted mean proportions of affected fish rose initially from about $9 \%$ at the shallowest $(<25 \mathrm{~m})$ depth range to peak at $67 \%$ in the $30-40 \mathrm{~m}$ range. However instead of a continuing increase in barotrauma signs at progressively greater depths, the incidence of observable external signs fell dramatically to around $20 \%$ in the $40-50 \mathrm{~m}$ range (Fig. 3 ).

\section{Discussion}

Our experiments showed the red emperor to be a relatively robust species and far less susceptible to the short-term effects of barotrauma than the closely related red snapper (Lutjanus campechanus) in the Gulf of Mexico. Rummer and Bennett (2005) found over $80 \%$ of

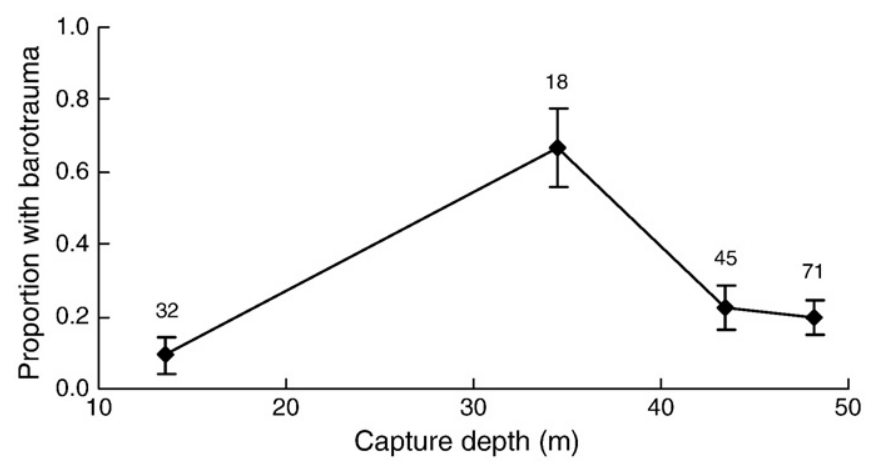

Fig. 3. Effect of capture depth on barotrauma signs in red emperor. Data points are the adjusted proportions of fish exhibiting external barotrauma signs at the mean reported depth in each of the four depth classes. Standard errors and sample sizes are also shown. the red snapper taken from depths of 30-60 m (similar to the depthrange from which our red emperor were caught) showed external signs of barotrauma, the most frequent being cloacal prolapse, exophthalmia and stomach eversion. Moreover, nearly a quarter of the vented fish died within an hour of the venting procedure, and another $10 \%$ died during transport or within $12 \mathrm{hr}$ of return to the laboratory (Rummer and Bennett, 2005). Although the only two red emperor that died during our experiments were individuals that had been released by shotline, the difference in survival rates between barotrauma-relief methods was not statistically significant.

If the severity of barotrauma is a function of depth, the occurrence of signs such as bloating and gut extrusion would be expected to increase as capture depth increases. While we found clear depthrelated differences in the frequency of external evidence of barotrauma in red emperor, the observed trends were not consistent with this expectation. Other studies suggest considerable variability between species in the relationship between barotrauma signs and capture depth. Progressive increases in the incidence of swim-bladder over-inflation, gut eversion and exophthalmia with increasing capture depth have been reported in West Australian dhufish (St John and Syers, 2005); tautog (Lucy and Arendt, 2002); and black, blue, and yelloweye rockfish, although not in the closely related canary rockfish (Hannah and Matteson, 2007). In laboratory decompression trials simulating a range of equivalent capture depths, Rummer and Bennett (2005) found no depth-related differences in external barotrauma signs in red snapper, despite considerable evidence of soft-tissue damage, high rates of short-term mortality, and a high frequency (80\%) of other barotrauma signs in fish subjected to pressure changes equivalent to a range of capture depths. Rudershausen et al. (2007) reported a positive association between capture depth and gastric distension in red grouper and gag; a negative association in vermilion snapper, red porgy and white grunt; and no statistical relationship in black sea bass or snowy grouper.

An explanation for external barotrauma signs being less frequent than expected in the red emperor (and some other species described above) when caught from deep water may relate to the circumstances surrounding and following swim bladder rupture. We suggest that there are three distinct stages of barotrauma with respect to the externally visible signs:

Stage 1: Initial inflation of the swim bladder in response to reduced ambient pressure. This leads to swelling or bloating of the body as the available space within the body cavity is progressively occupied by the expanding hydrostatic organ, as a result of which the fish becomes increasingly buoyant.

Stage 2: Swim bladder rupture. At a critical point the swim bladder ruptures and collapses, releasing gas directly into the body cavity. This is reported to occur in the red grouper at capture depth exceeding $20 \mathrm{~m}$ (Burns and Restrepo, 2002) and in the red snapper at depths greater than $30 \mathrm{~m}$ (Rummer and Bennett, 2005). If the swim bladder is strong and relatively inelastic, the increase in gas volume may be quite sudden and potentially traumatic to the fish. At this point the gas surrounds the visceral organs, taking up available space within the confines of the partly distensible body wall. Pressure exerted on the alimentary tract may result in intussusceptions, prolapses and evagination of parts of the gut through the mouth, gill chamber or cloaca.

Stage 3: Terminal rupture. When the body tissues can no longer constrain the increasing volume of gas, it then escapes to the exterior through rupturing of a distended part of the alimentary canal or body wall, possibly in the region between the pharynx and oesophagus. Fish with sharp dentition may puncture a ballooning oesophageal evagination if it extends out of the buccal cavity. The everted gut may then retract back into the body cavity, creating the impression of an absence of barotrauma effects, and the fish again becomes neutrally or even negatively buoyant.

The observed significant reduction in visible signs of barotrauma in red emperor caught from the deepest depth ranges is difficult to 
explain without invoking such a catastrophic loss of hydrostatic gas from the body. Our incidental observations on dissected red emperors revealed that swim-bladder rupture is not uncommon in this species. Of five fish sampled from the research catch at Double Island Pt, four showed evidence of swim bladder rupture with one or more perforations apparent in the ventral surface of the hydrostatic organ. All five, which ranged in size from 27 to $44 \mathrm{~cm}$ FL, had been captured at the same depth $(52 \mathrm{~m})$. The individual with the intact swim bladder was the second smallest of the sample $(33 \mathrm{~cm})$. The swim bladder of another small $(26.5 \mathrm{~cm} \mathrm{FL})$ red emperor taken from deeper water $(72 \mathrm{~m})$ off Double Island Pt in December 2006 had a $15 \mathrm{~mm}$ perforation in its ventral surface.

A number of physoclistous fish species have been observed releasing gas bubbles when being brought to the surface (Pearcy, 1992; Nichol and Chilton, 2006; Hannah et al., 2008), suggesting terminal rupture and release of swim bladder gas to the exterior. While Hannah et al. (2008) postulate that in yellowtail and quillback rockfish this may take place through perforations in the branchiostegal membrane, we were unable to find evidence in the red emperor of perforations either in the anterior alimentary canal or in the soft body wall behind the gill chamber.

Some species have the capacity to repair damaged swim bladders remarkably quickly. For example red grouper and red snapper are known to be able to seal large perforations in the swim bladder in four days or less (Burns and Restrepo, 2002), and Pacific cod within a period of 2-4 days (Nichol and Chilton, 2006). Parker et al. (2006) found that three-quarters of the china and black rockfish (Sebastes spp.) swim bladders which had ruptured during experimental decompression had at least partially healed and were holding gas by 21 days post-treatment. We suggest that the red emperor may also have the ability to heal damage to the swim bladder rapidly, although further investigation, perhaps using techniques similar to those described by Nichol and Chilton (2006), is needed to provide verification.

Insights into the longer-term survival of the released red emperor are emerging from the recreational angling Suntag ${ }^{3}$ database which contains information provided by many Queensland tag-and-release anglers. Since 2003 some 4740 red emperor have been tagged and released, and of these $514(10.8 \%)$ have been recaptured on at least one occasion. Eighty-one fish have been recaptured twice, 25 three times, 7 four times, 4 five times, and 4 on more than five occasions. Two individuals were recaptured on eight separate occasions over a 24 month period, and many of the recaptures occurred within days or even hours of release. Although the mean depth of capture was around $40 \mathrm{~m}$, very few of these tagged and released fish had been vented prior to release, and even fewer had been released by shotline, suggesting that this species is relatively resilient to the effects of barotrauma.

The evidence from our enclosure experiments and observations on the relationship between capture depth and barotrauma signs indicates that red emperor are resilient to the effects of capture, swim bladder inflation, and handling (including tagging), at least in the short term. This is in stark contrast to the situation with the congeneric $L$. campechanus as described by Rummer and Bennett (2005) and Rummer (2007), and highlights the large differences in susceptibility to catch-and-release injury that may exist between even closely related species (Parker et al., 2006; Jarvis and Lowe, 2008). Whether this short-term resilience translates into long-term post-release survival depends on many other factors that can influence survival over periods of weeks and months. However the high incidence of multiple recaptures reported by recreational anglers suggests that this species is well equipped physiologically to compensate for and recover from the effects of barotrauma. Analysis of 'historical' ( pre-2003) recreational tag-recapture data by Sumpton

\footnotetext{
${ }^{3}$ Infofosh Services, PO Box 9793 Frenchville, Queensland, Australia.
}

et al. (2008) suggested that venting provides a significant long-term survival benefit to red emperor, but a more recent and reliable data set with improved recording protocols failed to reproduce this finding (Sumpton et al., unpublished data). As mortality rates among the untreated controls were so low, our short-term experiments provide no compelling evidence for the use of either venting or shotline releasing to improve the survival of red emperor.

The results of the survival comparison were unequivocal. All fish in the cages had died after three days, while all of the fish in the vertical enclosures were alive and apparently healthy after the same period. This indicates that at least one key coral-reef species is capable of equilibrating at $15 \mathrm{~m}$ depth, even when caught from depths close to $50 \mathrm{~m}$ and released without venting or the aid of a shotline or release weight. The unexpectedly high mortality amongst fish in the enclosed cages is attributed to vertical movement of the cages as a result of swell and sea conditions. On retrieval all caged fish were in an advanced state of decomposition and showed signs of significant scale loss, probably as a result of abrasion against the mesh wall of the cage. Some evidence of abrasion of fish in the bottom-set cages was noted during experiments on the survival of the snapper and dhufish in Western Australia (Jill St John, pers. comm.), but Lucy and Arendt (2002) reported high survival rates among tautog held in cages on the sea-floor in Chesapeake Bay during rough sea conditions. The difference in survival rate of the red emperor between vertical enclosures and cages indicates that, at least in the sea conditions experienced in our study area, the former is far the more suitable for this type of experiment. On the basis of our results we strongly recommend the use of the vertical enclosure in experiments investigating the effects of barotrauma and potential treatments where there is a need for the test population to be restrained in captivity. One significant advantage of this apparatus is that it allows for experimental controls, a situation not possible where fish are forced to the bottom in enclosed cages.

\section{Role of the funding source}

The research presented in this report was made possible through funding from the Australian Government's Fisheries Research and Development Corporation. A sub-agency of the Corporation, the Released Fish Survival Steering Committee, assisted the Principal Investigator and other Project staff in certain aspects of the development of the project. One member of the Steering Committee (B. Sawynok) is a co-author of this paper.

\section{Contributors}

All authors have approved the article for publication. Individual author roles are as follows: Brown - principal investigator, project design and management, data analysis and interpretation, primary author; Sumpton - co-investigator, project design, field operations, data analysis and interpretation, manuscript drafting assistance; McLennan - project design, field operations and planning, data management, manuscript drafting assistance; Mayer - project and experimental design, data analysis and interpretation; Campbell project design, development of experimental apparatus, manuscript drafting assistance; Kirkwood - project design, field operations and planning, data analysis and interpretation, manuscript drafting assistance; Butcher - project design, field operations, data analysis and interpretation; Halliday - project design, field operations, data analysis and interpretation; Mapleston - project design, field operations and planning, data management, analysis and interpretation, manuscript drafting assistance; Welch - project design, field operations and planning, data management, analysis and interpretation, manuscript drafting assistance; Begg - project design, field operations, data analysis and interpretation, manuscript drafting assistance; Sawynok - project 
design, field operations and planning, tagging data management, manuscript drafting assistance.

\section{Conflict of interest}

To the best of our knowledge there are no actual or potential conflicts of interest relating to any of the authors of this paper that might have inappropriately influenced or biased their work.

\section{Acknowledgements}

We are grateful to Brett Davidson and Stelios Kondylas who expertly skippered the RV Tom Marshall during the field operations, and to the many recreational anglers and staff of both the Southern Fisheries Centre and the CRC for Reef Research who assisted with the tagging and experimental work. Thanks are due to Tony Stewart and his angling clients on the charter vessel Bait Runner for helping catch the fish, and to Kevin Henebery for providing samples from deep water for swim bladder dissection. We thank the members of the Released Fish Survival National Strategy Steering Committee for their support and advice throughout the project, and two anonymous reviewers for suggestions that improved the manuscript. Infofish Services principal Bill Sawynok provided access to the recreational tagging database. The research was conducted under the terms of a DPI\&F Community Access Animal Ethics Committee permit (Bribie 30/06/03) and was supported in part by a grant from the Australian Government's Fisheries Research and Development Corporation (FRDC 2003/019). [SS]

\section{References}

Bartholomew, A., Bohnsack, J.A., 2005. A review of catch-and-release angling mortality with implications for no-take reserves. Rev. Fish Biol. Fish. 15, 129-154.

Bruesewitz, R.E., Coble, D.W., Copes, F., 1993. Effects of deflating the expanded swim bladder on survival of burbot. N. Am. J. Fish. Manage. 13, 346-348.

Burns, K.M., Restrepo, V., 2002. Survival of reef fish after rapid depressurization: field and laboratory studies. Am. Fish. Soc. Symp. 30, 148-151.

Campbell, M.J., Sumpton, W.D., 2008. Ghost fishing in the pot fishery for blue swimmer crabs Portunus pelagicus in Queensland, Australia. Fish. Res. 95, 246-253.

Collins, M.R., 1991. Survival estimates for demersal reef fishes released by anglers. Proc. Gulf Caribb. Fish. Inst. 44, 259-269.

Collins, M.R., McGovern, J.C., Sedberry, G.R., Meister, H.S., Pardieck, R., 1999. Swim bladder deflation in black sea bass and vermilion snapper: potential for increasing postrelease survival. N. Am. J. Fish. Manage. 19, 828-832.

Cooke, S.J., Suski, C.D., Barthel, B.L., Ostrand, K.G., Tufts, B.L., Philipp, D.P., 2003. Injury and mortality induced by four hook types on bluegill and pumpkinseed. N. Am. J. Fish. Manage. 23, 883-893.

Diodati, P.J., Richards, R.A., 1996. Mortality of striped bass hooked and released in salt water. Trans. Am. Fish. Soc. 125, 300-307.

Feathers, M.G., Knable, A.E., 1983. Effects of depressurization upon largemouth bass N. Am. J. Fish. Manage. 3, 86-90.

Florida Sea Grant, 2005. Venting: a Guide to Releasing Reef Fish With Ruptured Swimbladders. Florida Sea Grant.

GenStat, 2007. GenStat for Windows. USN International Ltd Oxford.
Gotshall, D.W., 1964. Increasing tagged rockfish (genus Sebastodes) survival by deflating the swim bladder. Calif. Fish Game 50, 253-260.

Gravel, M.A., Cooke, S.J., 2008. Severity of barotrauma influences the physiological status, postrelease behavior, and fate of tournament-caught smallmouth bass. N. Am. J. Fish. Manage. 28, 607-617.

Grixti, D., Conron, S.D., Jones, P.J., 2007. The effect of hook/bait size and angling technique on the hooking location and the catch of recreationally caught black bream Acanthopagrus butcheri. Fish. Res. 84, 338-344.

Hannah, R.W., Matteson, K.M., 2007. Behavior of nine species of Pacific rockfish after hookand-line capture, recompression, and release. Trans. Am. Fish. Soc. 136, 24-33.

Hannah, R.W., Parker, S.J., Matteson, K.M., 2008. Escaping the surface: the effect of capture depth on submergence success of surface-released Pacific rockfish. N. Am. J. Fish. Manage. 28, 694-700.

Henry, G.W., Lyle, J.M., 2003. The national recreational and indigenous fishing survey. NSW Fisheries, Sydney.

Jarvis, E.T., Lowe, C.G., 2008. The effects of barotrauma on the catch-and-release survival of southern California nearshore and shelf rockfish (Scorpaenidae, Sebastes spp.). Can. J. Fish. Aquat. Sci. 65, 1286-1296.

Keniry, M.J., Brofka, W.A., Horns, W.H., Marsden, J.E., 1996. Effects of decompression and puncturing the gas bladder on survival of tagged yellow perch. N. Am. J. Fish. Manage. 16, 201-206.

Lucy, J.A., Arendt, M.D., 2002. Short-term hook release mortality in Chesapeake Bay's recreational tautog fishery. Am. Fish. Soc. Symp. 30, 114-117.

McCullagh, P., Nelder, J.A., 1989. Generalized Linear Models. Chapman and Hall, London.

Meka, J.M., 2004. The influence of hook type, angler experience, and fish size on injury rates and the duration of capture in an Alaskan catch-and-release rainbow trout fishery. N. Am. J. Fish. Manage. 24, 1309-1321.

Muoneke, M.I., Childress, W.M., 1994. Hooking mortality: a review for recreational fisheries. Rev. Fish. Sci. 2, 123-156.

Nichol, D.G., Chilton, E.A., 2006. Recuperation and behaviour of Pacific cod after barotrauma. ICES J. Mar. Sci. 63, 83-94.

Parker, S.J., McElderry, H.I., Rankin, P.S., Hannah, R.W., 2006. Buoyancy regulation and barotrauma in two species of nearshore rockfish. Trans. Am. Fish. Soc. 135,1213-1223.

Pearcy, W.G., 1992. Movements of acoustically-tagged yellowtail rockfish Sebastes flavidus on Hecate Bank. Oregon. Fish. Bull. 90, 726-735.

Pollock, K.H., Pine III, W.E., 2007. The design and analysis of field studies to estimate catch-and-release mortality. Fish. Manage. Ecol. 14, 123-130.

Render, J.H., Wilson, C.A., 1994. Hook-and-line mortality of caught-and-released red snapper around oil and gas platform structural habitat. Bull. Mar. Sci. 55, 1106-1111.

Rogers, B.L., Lowe, C.G., Fernández-Juricic, E., Frank, L.R., 2008. Utilizing magnetic resonance imaging (MRI) to assess the effects of angling-induced barotrauma on rockfish (Sebastes). Can. J. Fish. Aquat. Sci. 65, 1245-1249.

Rudershausen, PJ., Buckel, J.A., Williams, E.H. 2007. Discard composition and release fate in the snapper and grouper commercial hook-and-line fishery in North Carolina, USA. Fish. Manage. Ecol. 14, 103-113.

Rummer, J.L., 2007. Factors affecting catch and release (CAR) mortality in fish: insight into CAR mortality in red snapper and the influence of catastrophic decompression. Am. Fish. Soc. Symp. 60, 113-132.

Rummer, J.L., Bennett, W.A., 2005. Physiological effects of swim bladder overexpansion and catastrophic decompression on red snapper. Trans. Am. Fish. Soc. 134, 1457-1470.

St John, J., Syers, C.J., 2005. Mortality of the demersal West Australian dhufish, Glaucosoma hebraicum (Richardson 1845) following catch and release: the influence of capture depth, venting and hook type. Fish. Res. 76, 106-116.

Stewart, J., 2008. Capture depth related mortality of discarded snapper (Pagrus auratus) and implications for management. Fish. Res. 90, 289-295.

Sumpton, W., Mayer, D., Brown, I., Sawynok, B., McLennan, M., Butcher, A., Kirkwood, J., 2008. Investigation of movement and factors influencing post-release survival of linecaught coral reef fish using recreational tag-recapture data. Fish. Res. 92, 189-195.

Wilde, G.R., 2009. Does venting promote the survival of released fish? Fisheries 34, 20-28.

Wilson Jr., R.R., Burns, K.M., 1996. Potential survival of released groupers caught deeper than $40 \mathrm{~m}$ based on shipboard and in-situ observations, and tag-recapture data. Bull. Mar. Sci. 58, 234-247. 